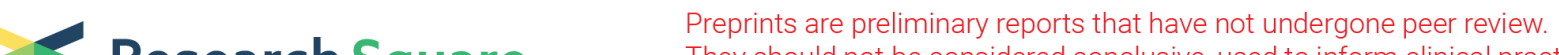 $\begin{array}{ll}\text { Research Square } & \text { They should not be considered conclusive, used to inform clinical practice, } \\ \text { or referenced by the media as validated information. }\end{array}$
}

\section{Online, face-to-face, or blended learning? Faculty and medical students' perception during the COVID- 19 pandemic: A mixed-method study}

Hani Atwa ( $\sim$ doctorhani2000@yahoo.com )

Arabian Gulf University

Mohamed Hany Shehata

Arabian Gulf University

Ahmed Al-Ansari

Arabian Gulf University

Archana Kumar

Arabian Gulf University

Ahmed Jaradat

Arabian Gulf University

Jamil Ahmed

Arabian Gulf University

Abdelhalim Deifalla

Arabian Gulf University

\section{Research Article}

Keywords: Face-to-face, online, COVID-19 adaptations, blended learning, COVID-19 experience

Posted Date: October 1st, 2021

DOl: https://doi.org/10.21203/rs.3.rs-951471/v1

License: (c) (i) This work is licensed under a Creative Commons Attribution 4.0 International License.

Read Full License

Version of Record: A version of this preprint was published at Frontiers in Medicine on February 3rd, 2022. See the published version at https://doi.org/10.3389/fmed.2022.791352. 


\section{Abstract}

Background: The COVID-19 pandemic forced educational institutions to adopt online methods which were inevitable to keep the continuity of education across all academia after the suspension of traditional educational systems. The aim of this study was to explore the experience of faculty and students of online learning and their preference of the mode of learning after the pandemic.

Methods: This is a mixed-method study that encompassed a quantitative component (researcher-made survey consisting of 22 items under three domains) and a qualitative component (focus group discussions). Quantitative data analysis was done, and quantitative variables were presented as means and standard deviations. Paired samples t-test and Chi-square test were used. A p-value $₫ 0.05$ was considered as a cut-off point of statistical significance. Thematic analysis of qualitative data was used to code, interpret, and make sense of the data.

Results: The mean scores of responses of faculty members and students were in favor of face-to-face and blended learning compared to online learning in all survey items with a statistically significant difference. More than half of the students preferred the face-to-face mode of learning, while most of the faculty preferred the blended mode of learning.

Qualitative analysis identified five themes and revealed suggestions that at least $30 \%$ of the curriculum could be taught online post-COVID-19. Some aspects of clinically oriented teaching including history taking and case discussions can also be delivered online in the future. Faculty members and students reported that dealing with online education was not difficult, although the transition was not smooth.

Conclusion: The study revealed that although online learning is the possible educational adaptation during the pandemic, medical students and faculty still prefer face-to-face and blended modes of learning for their higher benefits.

\section{Introduction}

The COVID-19 pandemic affected the normal functioning of all academic institutions globally [1]. Health professions educational institutions were disturbed to the maximum, obviously more than other education institutions. This is mainly because of the inherent nature of teaching and learning in such institutions, which depends mainly on the contact between the teachers, students, and patient in training sites $[2,3]$.

Lockdown measures were implemented in all countries, which forced educational institutions to search for alternatives for continuing their educational programs without compromising the safety of their students and teachers [4-6].

Very soon, it became apparent that the judicious use of technology could solve many of the problems, and therefore, almost all educational institutions initiated a paradigm shift in their policies to rapidly 
introduce online methods for teaching as well as assessment [7-10]. Adapting online methods was inevitable to keep the continuity of education across all academia [11-13].

Medical schools witnessed additional responsibility to continue with the curriculum, to enable timely graduation of the students of 2020, in order to support the overwhelmed healthcare systems battling the pandemic $[14,15]$. The College of Medicine and Medical Sciences at the Arabian Gulf University (CMMSAGU) was among the first institutions in the region that embraced this transition very systematically [16].

Few studies have already documented the preferences of students for online or face-to-face learning for different reasons. Students preferred online learning for providing well-structured learning materials and enabling studying from home at their own pace and convenience. At the same time, they also liked faceto-face learning for specific reasons like acquiring motor skills and establishing interpersonal relations $[17,18]$.

Some authors have recognized that in courses that are more practical / skill oriented, changing entirely to online mode may not be a viable option and such institutions ought to design a hybrid / blended curriculum involving both face-to-face and online methods [19].

There are diverse opinions about the quality and study outcomes of online learning because some authors feel that they are less efficient while others believe that there is no significant difference when compared to face-to-face teaching [20].

Even though the short-term outcomes of the crisis management of educational activities at CMMS-AGU were encouraging, experts always recommend introspecting experience and based on which envisage a strategic plan to accomplish long term goals in terms of utilizing face-to-face and online methods [21, 22].

The aim of this study was to explore the overall experience of both medical students and faculty members of online teaching/learning and assessment, and their preference of the mode of learning (online, face-to-face, or blended) after the pandemic.

We expect that this will help us evaluate the experience of CMMS-AGU in the sudden shift from face-toface to online learning during the COVID-19 pandemic, and to guide the teaching and learning practices in reforming the medical curricula to cater the graduation of the future-ready doctors.

\section{Materials And Methods}

Study design:

This is a mixed-method study which encompassed a quantitative component (researcher-made survey) and a qualitative component (focus group discussions for faculty members and medical students).

Study setting and context: 
The study was conducted at the College of Medicine and Medical Sciences, Arabian Gulf University (CMMS-AGU) to report the College's experience in dealing with the sudden digital transformation in higher education that was mandated by the COVID-19 pandemic. Before the pandemic, teaching/learning and assessment practices were conducted completely face-to-face at the CMMS-AGU campus and its affiliated clinical settings.

\section{Participants:}

In the quantitative part, all faculty members and students (except first year students who just joined the program) at the CMMS-AGU were invited to participate in this study through responding to the online survey. Fourteen faculty members and 10 students participated in the focus group discussions (FGDs). Faculty who participated in the FGDs were nominated by the CMMS-AGU administration to represent all academic departments, while the selected students were originally the representatives of their batches in the students' council.

\section{Tools for data collection:}

Data for the study was collected in the period from October to December 2020. Quantitative data in this study was collected through a unified survey form for both students and faculty members. The survey was drafted by the study team, based on review of relevant literature and other similar survey instruments [23-28]. Every item was discussed in detail and changes were made wherever appropriate (addition, deletion, or editing of some items). It was then transformed to an online form through Google Forms. The survey consisted of 22 items under three domains, which are: Social Presence and Interaction, Collaborative Learning, and Satisfaction. In addition, six open-ended questions were added to the survey to allow students and faculty members to freely express their viewpoints on the advantages and challenges of face-to-face and online learning, in addition to their suggestions for reform of both learning strategies. Face and content validity of the survey form was established through revision by three experts from the Medical Education Unit of the AGU. Reliability of the survey was tested through Cronbach's alpha test and was found to be 0.98 , which indicate excellent consistency of the survey.

For qualitative data collection, a total of four FGDs were conducted through Zoom ${ }^{\mathrm{TM}}$ (Zoom Video Communications, Inc., San Jose, CA, USA); two with faculty members only and another two with undergraduate medical students only. Mixing faculty members and students in the same FGD was avoided to prevent possible bias and nervousness, especially from the side of the students. Faculty members represented various department of the College of Medicine and Medical Sciences, and students represented various undergraduate batches. The participants were informed about the purpose of the study and a verbal consent was obtained. A semi-structured field guide was used to encourage discussion around topics identified through a literature search and opinion of the team. Development of the guide was informed by the quantitative findings. The guide was reviewed and approved by the study team who comprised of three medical education experts. Each FGD extended over 45 minutes, and was conducted in English, recorded, and then transcribed. 
Data analysis:

Quantitative data analysis was done using the Statistical Package for the Social Science (SPSS) for Windows, version 27 (SPSS Inc., USA). Quantitative variables were presented as means and standard deviations. Paired samples t-test was used to compare between the mean response of faculty members and students on face-to-face and online learning. Chi-square test was used to compare the differences of responses of faculty members and students regarding their preference of online, face-to-face, and blended learning. A $p$-value $₫ 0.05$ was considered as a cut-off point of statistical significance.

For qualitative data analysis, three support staff members transcribed the recordings verbatim. We used thematic analysis method to code, interpret and make sense of the data by using QSR NVivo version 12. The analysis was based on thematic analysis principles described by Braun and Clarke [29]. Although a deductive approach was used to interpret data where we drew items from within the FGD guides, but an inductive approach was also used, where the themes - pattern within data answering our research objectives-were generated from within the data itself. One of the authors first thoroughly read the text to familiarize with the data and then coded the text in NVivo. The codes were then checked again, revised, and merged into appropriate thematic ideas or categories. In the next step, the data were interpreted, and themes were revised by refining their names to develop a construct that could best answer the research question. Themes were checked for internal homogeneity and external heterogeneity by reading the codes and a word search.

\section{Ethical approval:}

Ethical approval was obtained from the Research and Ethics Committee of the College of Medicine and Medical Sciences, Arabian Gulf University.

\section{Results}

The number of participants who responded to the survey was 33 faculty members out of the total of 56 (response rate was 59\%) and 194 students out of 842 (response rate was 23\%). Out of the 14 faculty members invited to participate in the FGDs, 13 attended and actively participated (response rate was 93\%). Out of the 10 students invited to participate in the FGDs, 9 attended and actively participated (response rate was $90 \%$ ).

The results are presented here in three sections as follows:

\section{Section I: Characteristics of Study Participants:}

Faculty members from all academic ranks (15.2\% full professors, $30.3 \%$ associate professors, $30.3 \%$ assistant professors, and $24.2 \%$ lecturers) represented all the departments of the CMMS-AGU. Also, students represented all years of the medicine program (5.7\% second year, $20.6 \%$ third year, $24.2 \%$ fourth year, $11.3 \%$ fifth year, and $38.1 \%$ sixth year). First year students were not included as they were still 
freshmen who just came from high school and they did not experience the two modes of learning (online and face-to-face) at CMMS-AGU.

\section{Section II: Students' and Faculty Members' Responses to the Survey:}

Paired samples t-test was used to compare the differences of mean scores of responses of faculty members and students regarding both online and face-to-face learning. The results indicate that the mean scores of responses of both faculty members and students were higher for face-to-face learning that for online learning for all the survey items. The differences were statistically significant $(p<0.05)$ for almost all the items. The lowest scores were reported by the students in the areas related to interaction with other students and teachers, as well as the learning environment and its impact (items 4, 6, 7, 8, 11, and 20) (Table 1).

Table 1: Comparison between Responses of Faculty and Students on Online and Face-to-Face Learning: 
Faculty $(n=33)$

Online

Mean

$( \pm S D)$
Face
to-
Face

Mean

$( \pm S D)$
Students $(n=194)$

Online Face-

to-

Mean Face

$( \pm S D)$

Mean

$( \pm S D)$

1- Introductions between students and faculty at the beginning of the course create a sense of community
3.70
4.73
$( \pm 1.05) \quad( \pm 0.52)$
$0.000 *$
3.24
$( \pm 1.41)$
4.08
$( \pm 1.05)$
$0.000 *$

2- The instructors facilitate

discussions in the sessions

4.18

$( \pm 0.88)$

4.61

$( \pm 0.70)$

$0.024 *$

3.40

$( \pm 1.35)$

4.14

$( \pm 0.95)$

3- Students' points of view are respected by their colleagues in the

4.03

4.45

$( \pm 0.81)$

$( \pm 0.56)$

$0.008^{*}$

3.70

$( \pm 1.32$

4.24

$( \pm 0.87)$

value

sessions

4- Courses create a suitable

environment for social interaction

between students

$\begin{array}{lllll}3.30 & 4.39 & 0.000 * & 2.88 & 4.20 \\ ( \pm 1.07) & ( \pm 0.75)\end{array} \quad \begin{array}{lll}( \pm 1.49) & ( \pm 0.99)\end{array}$

$0.000 *$

5- It is comfortable for students to

interact in the sessions

3.73

4.24

$( \pm 1.04)$

$( \pm 0.75)$

$0.036^{*}$

3.36

$( \pm 1.55)$

3.89

$( \pm 1.17)$

6- The amount of interaction with

other students in the sessions is

3.33

4.30

$( \pm 0.99)$

$( \pm 0.73)$

$0.000 *$

2.97

$( \pm 1.40)$

4.01

$( \pm 1.04)$

$0.000 *$

appropriate

7- The quality of interaction with other

students in the sessions is appropriate

3.39

4.30

$0.000^{*}$

2.95

4.01

$( \pm 1.41)$

$( \pm 1.06)$

8- Strong social relationships can be

built during the courses

3.24

4.30

$( \pm 1.03) \quad( \pm 0.98)$

$0.000^{*}$

2.46

$( \pm 1.35)$

4.26

$( \pm 1.01)$

\section{Social Presence and Interaction}

3.61

4.42

$0.000 *$

3.12

$( \pm 1.16)$

4.10

$( \pm 0.68) \quad( \pm 0.60)$

9- The students can feel part of a

learning community in the courses

3.97

4.55

$( \pm 0.68) \quad( \pm 0.67)$

$0.000 *$

3.07

$( \pm 1.46)$

4.32

$( \pm 0.91)$

10- The students can actively

exchange ideas in the courses

\subsection{4}

$( \pm 0.97)$

4.55

$0.003^{*}$

$( \pm 0.67)$

3.08

$( \pm 1.44)$

4.18

$( \pm 0.94)$

11- The students can develop new

skills and knowledge from other

members in the courses

12- The students can develop problem-

solving skills through peer

collaboration during sessions

13- Collaborative learning in the

3.45

$( \pm 0.97)$

4.30
$( \pm 0.85)$

$0.000 *$

2.97

$( \pm 1.47)$

4.33

$( \pm 0.95)$

0.000 *

$0.002^{*}$

$0.000 *$

(2.000*

courses is effective

3.79

$( \pm 0.86)$

4.45

$( \pm 0.71)$

$0.001^{*}$

3.11

$( \pm 1.45)$

4.26

$( \pm 0.94)$

$0.000 *$

14- Students save time with

collaborative learning in the courses

3.76

$( \pm 0.66)$

3.85

$( \pm 0.80) \quad( \pm 0.98)$

Page $7 / 19$

4.30

$( \pm 0.81)$
$0.002 *$

3.10

$( \pm 1.43)$

4.19

$( \pm 1.00)$

0.763

3.54

$( \pm 1.49)$

$0.000 *$

$0.000 *$

$0.000 *$

$0.000 *$

0.000 *

0.000 *

0.000 


\begin{tabular}{|c|c|c|c|c|c|c|}
\hline $\begin{array}{l}\text { 15- Overall, collaborative learning } \\
\text { experience in the courses is satisfying }\end{array}$ & $\begin{array}{l}3.64 \\
( \pm 0.74)\end{array}$ & $\begin{array}{l}4.21 \\
( \pm 0.74)\end{array}$ & $0.001^{*}$ & $\begin{array}{l}3.16 \\
( \pm 1.41)\end{array}$ & $\begin{array}{l}3.93 \\
( \pm 1.12)\end{array}$ & $0.000 *$ \\
\hline Collaborative Learning & $\begin{array}{l}3.77 \\
( \pm 0.6)\end{array}$ & $\begin{array}{l}4.32 \\
( \pm 0.67)\end{array}$ & 0.000 & $\begin{array}{l}3.15 \\
( \pm 1.29)\end{array}$ & $\begin{array}{l}4.10 \\
( \pm 0.86)\end{array}$ & $0.000 *$ \\
\hline $\begin{array}{l}\text { 16-Students can learn effectively from } \\
\text { the sessions }\end{array}$ & $\begin{array}{l}4.06 \\
( \pm 0.70)\end{array}$ & $\begin{array}{l}4.33 \\
( \pm 0.65)\end{array}$ & $0.048 *$ & $\begin{array}{l}3.29 \\
( \pm 1.51)\end{array}$ & $\begin{array}{l}4.12 \\
( \pm 1.08)\end{array}$ & $0.000 *$ \\
\hline $\begin{array}{l}\text { 17- Students are stimulated to do } \\
\text { additional reading or research on } \\
\text { topics discussed in the courses }\end{array}$ & $\begin{array}{l}4.00 \\
( \pm 0.79)\end{array}$ & $\begin{array}{l}4.24 \\
( \pm 0.83)\end{array}$ & 0.058 & $\begin{array}{l}3.37 \\
( \pm 1.46)\end{array}$ & $\begin{array}{l}4.02 \\
( \pm 1.12)\end{array}$ & $0.000 *$ \\
\hline $\begin{array}{l}\text { 18-Discussions assist students in } \\
\text { understanding other points of view }\end{array}$ & $\begin{array}{l}4.21 \\
( \pm 0.60)\end{array}$ & $\begin{array}{l}4.42 \\
( \pm 0.66)\end{array}$ & 0.090 & $\begin{array}{l}3.41 \\
( \pm 1.41)\end{array}$ & $\begin{array}{l}4.19 \\
( \pm 0.95)\end{array}$ & $0.000 *$ \\
\hline $\begin{array}{l}\text { 19- The level of learning that takes } \\
\text { place in the courses is of high quality }\end{array}$ & $\begin{array}{l}3.94 \\
( \pm 0.83)\end{array}$ & $\begin{array}{l}4.30 \\
( \pm 0.81)\end{array}$ & $0.003^{*}$ & $\begin{array}{l}3.17 \\
( \pm 1.52)\end{array}$ & $\begin{array}{l}4.09 \\
( \pm 1.09)\end{array}$ & $0.000 *$ \\
\hline $\begin{array}{l}20 \text { - Learning environment in the } \\
\text { sessions is motivating }\end{array}$ & $\begin{array}{l}3.76 \\
( \pm 0.83)\end{array}$ & $\begin{array}{l}4.33 \\
( \pm 0.74)\end{array}$ & $0.001^{*}$ & $\begin{array}{l}2.85 \\
( \pm 1.57)\end{array}$ & $\begin{array}{l}3.99 \\
( \pm 1.17)\end{array}$ & $0.000 *$ \\
\hline $\begin{array}{l}\text { 21- Overall, the courses satisfy the } \\
\text { students' learning expectations }\end{array}$ & $\begin{array}{l}3.70 \\
( \pm 0.81)\end{array}$ & $\begin{array}{l}4.27 \\
( \pm 0.72)\end{array}$ & $0.000 *$ & $\begin{array}{l}3.08 \\
( \pm 1.54)\end{array}$ & $\begin{array}{l}4.08 \\
( \pm 1.05)\end{array}$ & $0.000 *$ \\
\hline Satisfaction & $\begin{array}{l}3.90 \\
( \pm 0.78)\end{array}$ & $\begin{array}{l}4.34 \\
( \pm 0.73)\end{array}$ & $0.001 *$ & $\begin{array}{l}3.19 \\
( \pm 1.51)\end{array}$ & $\begin{array}{l}4.08 \\
( \pm 1.08)\end{array}$ & $0.000 *$ \\
\hline Overall & $\begin{array}{l}3.76 \\
( \pm 0.89)\end{array}$ & $\begin{array}{l}4.34 \\
( \pm 0.77)\end{array}$ & $0.000 *$ & $\begin{array}{l}3.15 \\
( \pm 1.47)\end{array}$ & $\begin{array}{l}4.09 \\
( \pm 1.05)\end{array}$ & $0.000 *$ \\
\hline
\end{tabular}

* Statistically Significant

Figure 1 shows the mean scores of responses of faculty members and students in relation to the studied domains (Social Presence and Interaction, Collaborative Learning, and Satisfaction) and the Overall Experience. The mean scores of faculty members are consistently higher than those of students for both online and face-to-face learning. The differences were statistically significant $(p<0.05)$.

It is clear from the figure that the mean scores for face-to-face learning for both faculty members and students are higher than the mean scores for online learning, indicating that both faculty members and students are more in favor of face-to-face than online learning.

Chi-square test of the preference of the mode of learning revealed a statistically significant difference between the preferences of faculty members and students $(p<0.05)$. More than half of the students preferred face-to-face mode of learning, while most of the faculty preferred the blended mode of learning. On the other hand, only a small percentage of faculty members preferred online mode of learning compared to one third of the students (Table 2). 
Table 2: Comparison of Responses of Faculty Members and Students Regarding Preference of the Mode of Learning:

\begin{tabular}{|c|c|c|c|c|}
\hline Mode of Learning & $\begin{array}{l}\text { Faculty Members } \\
(n=33)\end{array}$ & $\begin{array}{l}\text { Students } \\
(n=194)\end{array}$ & $\mathrm{Chi}^{2}$ & $\begin{array}{l}\text { Sig. } \\
\text { (p-value) }\end{array}$ \\
\hline Online & $1(3.0 \%)$ & $57(29.4 \%)$ & 47.8 & $0.000 *$ \\
\hline Face-to-Face & $12(36.4 \%)$ & $103(53.1 \%)$ & & \\
\hline Blended & 20 (60.6\%) & 34 (17.5\%) & & \\
\hline
\end{tabular}

* Statistically Significant

\section{Section III: Summary of Qualitative Results (}

Qualitative analysis revealed five interrelated but distinct themes, namely: 1. Transforming the way theoretical teaching sessions are given, 2. Face to face teaching at campus cannot be replaced for some type of education, 3. Interaction in online sessions is limited, 4. Problems and challenges of online examinations, and 5. Technical issues and challenge of online education (Table 3).

Table 3: List of Codes and Categories Forming the Final Themes in the Qualitative Analysis: 
- Improving the quality of theoretical lessons.

- Participation in online resources has improved.

- Recorded theoretical teaching sessions are preferred.

- Teaching that should be given online.

- Attending from home is preferred.

- Future is for blended learning.

- Time and effort saved in online learning.

- Online learning complements faceto-face.

- Dressing up and surroundings for online sessions.
- Teaching that should be given online.

- Time and effort saved in online learning.

- Recorded theoretical teaching sessions are preferred.

- Improving resource session quality.

\section{Theme 1:}

Transforming the way theoretical teaching sessions are given.
- Face-to-face teaching/learning has its limitations.

- Communication is better built with face-to-face learning.

- Professional (practical) skills training must be given at the campus.

- Direct participation in face-to-face is better than in online.

\section{Theme 2:}

- In-person participation in face-toface is better than in online.

- Communication is better built with face-to-face learning.

- Clinical training, laboratory and professional (practical) skills, and tutorials must be conducted face-toface.
Face-to-face teaching at campus cannot be replaced for some types of education.
- Quality of presentations in face-to-face teaching.

- Interaction in sessions.

- Student's presence in the sessions.

\section{Theme 3:}

- Interaction in sessions.

- Students' presence in online sessions.

Interaction in online sessions is limited.

- Valuing the direct human interactions and socializing. 
- Attending campus is much better.

- Achievement in assessments.

- Achieving the transparency in online examinations.

- Setting online examinations is challenging.
- Challenges of online examination.

- Assessment issues.

\section{Theme 4:}

Problems and challenges of online examinations.
- Initial challenges to going online.

- Technical issues and support required.
- Initial problems to go online.

- Support required for technical issues.

\section{Theme 5:}

Technical issues and challenge of online education.

\section{Theme (1): Transforming the way theoretical teaching sessions are given:}

Faculty members in the FGDs proposed that at least $30 \%$ of the curriculum could be given online postCOVID-19 as it saves a lot of time and effort. Some aspects of the clinically oriented teaching including history taking and case discussions can also be delivered online in the future. For the subjects requiring teaching in a clinical setting or patient exposure, participants clearly indicated that student presence at the campus would be crucial to meet the learning objectives.

"I can confidently say that $30 \%-40 \%$ of the curriculum can be given online".

"Subjects like Physiology and Biochemistry that can be taught online easily." (Faculty members - FGD 1)

Students believed that although online teaching was useful, and complemented their learning, they felt that it should be used as a standby plan for face-to-face teaching. The participants agreed that with the shift to online teaching during the COVID-19 pandemic, the students have most sessions recorded so they can watch them multiple times, which gives them time to absorb the ideas in the lecture.

"I do not depend on the videos entirely. I first watch the lectures, and it is good because if you want to study something you can go back and watch it repeatedly until you understand it." (Student - FGD 2)

The participants also discussed the need to standardize and revamp the quality of the theoretical teaching sessions. The students reported that faculty members have a wide range of teaching approaches in the classroom and there was no one standard that everyone follows.

"Some teachers explain very well and some of them (are just) ok, but I always have to go to watch a video for the complex concepts." (Student - FGD 2) 


\section{Theme (2): Face-to-face teaching at campus cannot be replaced for some types of education:}

Most of the participants agreed that online teaching methods may not help achieve the intended learning outcomes compared to face-to-face teaching. A faculty member believed that responding to questions by students is easier during face-to-face teaching. Clinical faculty members confirmed that it was clear that clinical skills are difficult to be imparted online. They believed that the theoretical teaching is only a part of clinical training, while it would require students to be present and practically perform a procedure in front of their tutors to learn a particular clinical skill. Direct feedback on clinical examinations and procedures can only be given when they are conducted face-to-face in front of the tutors.-

"For surgical skills, like suturing, how can you teach this to students online? I can only give them the basic theoretical background online, but for the actual act and performance, you need to touch the patients or models physically." (Faculty member - FGD 1)

Similarly, faculty members and students unambiguously identified problems with the problem-based tutorial sessions conducted online, as they believed that these sessions are best conducted face-to-face with direct interaction between students with each other and students with their teachers. Apart from the claim that the problem-based tutorial sessions are useful face-to-face, the students believed that they are also more enjoyable because sitting physically with colleagues gives an opportunity to students to get to know and meet with their friends.

"When it comes to the online tutorial sessions, I do not feel that it is that interactive or focused. I present and then I can go do something else away from the computer." (Student - FGD 2)

\section{Theme (3): Interaction in online sessions is limited:}

Students' perceptions of quality of theoretical teaching sessions they used to have face-to-face in the classrooms before the shift to the online mode during the pandemic showed that they value more interaction.

"Using the pen and the smart screens and drawing on the white board in the classroom make the interaction very much better, valuable, and helpful and help us understand better." (Faculty member FGD 1)

Faculty members and students discussed how valuable was interaction out of the classroom and that they missed talking to their peers since online teaching was implemented during the COVID-19 pandemic. Being present in the campus helps students interact with other students and build relationships that are difficult to be built online.

"We used to meet and spend good time together, and personally, I used to study in the library with my friends. I see everyone studying and that encourages me to study as well." (Student - FDG 2) 
Faculty members believed that nurturing communication skills in medical undergraduate students through physical interaction is crucial for them to be prepared to face patients in the future.

"Medical students are not supposed to just acquire knowledge in online sessions, but they also need to learn communication skills through direct (face-to-face) interaction with their colleagues and teachers. They need that ... they will face people and interact with patients." (Faculty member - FGD 1)

\section{Theme (4): Problems and challenges of online examinations:}

Faculty members were concerned about the quality of the examinations held online and whether the online examinations can properly assess students' knowledge. The first concern about examinations was whether the student knowledge has improved as reflected by the inflated marks they get in online examinations. Faculty members believed that students were securing about most of the marks in their multiple-choice question-based examinations because these were much easier compared to on campus examinations conducted before. Another participant informed that almost one third of the students could secure full marks, which has never happened before. Participants justified the inflated results by the fact that the online examinations do not contain supply-type questions in which students used to lose marks. A faculty member believed that the inflated marks could also have resulted from the online assessment of some clinical skills, in which students received higher marks.

"I do not believe that whatever the quality of the multiple-choice exams we prepare we can be confident that the real achievement of the learning outcomes by the students is guaranteed.

Other question types and assessment methods are always needed." (Faculty member - FGD 1)

Students were concerned about the online examinations as they appeared to be dissatisfied with the time allocated for completing them, which is shorter than in the normal conditions where the exams are on campus and proctored. Another issue they identified was that they were not able to go back to a previous question to correct it whenever needed, a feature that was adjusted in the online examinations platform to prevent or reduce cheating possibilities.

"In an exam, we were given 40 questions in one hour, so we have to give each question one and a half minutes, which was not sufficient for answering some complex questions." (Student - FGD 1)

\section{Theme (5): Technical issues and challenge of online education:}

Communication technology issues were listed, by both the faculty members and students alike, as one of the main challenges of online education that took place in response to the sudden shift from face-to-face to online education. Initially, faculty members were recording their lectures through adding voice to the PowerPoint slides and sharing the recording with the students through cloud sharing platforms. Faculty members termed this initial interaction with students as "not actually virtual teaching" but rather a teaching based only on "recordings". Challenges of recordings included issues with the length and quality of videos and voice as well as inability of the students to ask questions. Shortly, faculty members started to conduct synchronous live sessions with their students, where they could interact with them and could 
answer their questions and provide further instructions whenever needed. The important issue that popped up at that stage was the unstable internet speed that affected the live streaming of educational sessions. Faculty members and students reported that dealing with online education was not difficult, although the transition was not smooth.

"I always make sure my students can hear me before I go on and on in the session. It is important to guarantee every single student is following instruction." (Faculty member - FGD 1)

\section{Discussion}

This study employed a mixed method design and aimed at exploring the overall experience of both medical students and faculty members of online teaching/learning and assessment, and their preference of the mode of learning (online, face-to-face, or blended) after the pandemic. The study also explored the perceptions of participants regarding the improvements based on this experience that might enhance the learning experience in the post-COVID era.

Comparing the perception of the faculty members and students of face-to-face and online learning regarding the studied domains (Social Presence and Interaction, Collaborative Learning, and Satisfaction) and the Overall Experience revealed consistently higher mean scores for face-to-face learning than online learning. Outputs from FGDs support these results, where generally both faculty members and students preferred face-to-face learning over online learning. This is especially true when it comes to clinical and practical sessions, which is expected as physical examination skills cannot be learned without physical contact between students and real or simulated patients. The FGDs failed to suggest alternative strategies to replace face-to-face learning in this regard.

More than half of the students preferred face-to-face learning to online and even blended learning modes. This agrees with a pre-COVID study by Keis et al. [30], who reported higher satisfaction of their students by the face-to-face mode of learning. A recent study by Muthuprasad et al. [19] reported that most students showed a positive attitude towards online learning during the COVID-19 pandemic. One reason for that might be that online and blended learning modes are new to the students and they are not fully aware of the benefits of something they have not tried before. Another reason may be students' feeling that in a medical school everything should be taught face-to-face. However, a notable percentage of students in our study preferred online learning. This might be related to the fact that a big number of students in our college come from at least five countries to live and study in the college in Bahrain. Those students most probably prefer online learning because it allows them to study while they are at their home countries enjoying their families' significant moral and social support [31]. Also, an explanation might be that students in online learning have access to more resources and they can study on their own pace.

In a pre-COVID study conducted on a large sample of Austrian students by Paechter and Maier [17], it was found that students appreciated online learning for its potential to provide a coherent structure of learning and supporting self-regulated learning. However, they preferred face-to-face learning for 
providing better communication and interaction, in addition to establishing better interpersonal relations and allowing for cooperative learning. This is clear from the lower mean scores of students' perception in most survey items that are related to interaction, social relations, and learning environment.

On the other hand, most of the faculty members preferred blended learning. This is supported by the results of a study by Lapitan et al. [32], where they reported that a newly developed blended method of learning had positive impact on both teachers and students. This might be due to the flipped nature of blended learning, where the students can learn the theoretical part of lessons before coming to the classroom to do practical exercises facilitated by the teachers [33,34]. This is supported also by results from focus group discussions, where teachers reported that it would be better to mix between online learning for the theory parts of lessons (where students can do on their own pace before class) and faceto-face learning for deeper and more practical teaching in the classroom. However, more than one third of faculty members preferred face-to-face teaching. Reasons might be that this is the mode with which they are familiar and the fact that they were not ready for teaching online.

The five themes generated from the FGDs, in general, cover the different aspects of perceiving face-toface and online learning by both faculty members and students and indicates a more positive attitudes towards face-to-face learning, which triangulates with the results of the survey and analysis of students' performance in face-to-face and online exams, which indicates the consistency of the study results.

\section{Conclusions}

The study revealed that although online learning is the possible educational adaptation during the pandemic, faculty and students still prefer face-to-face and blended learning. Qualitative analysis supported the quantitative results and revealed that both faculty and students agree on the benefits of online learning but prefer face-to-face and blended modes for their higher benefits. Educational adaptation in the form of online learning is obligatory during pandemics and suspension of traditional (face-to-face) education as an alternative to maximize the safety of all stakeholders and provide an easy and timely access to educational material and sessions, but this will not make such adaptation the future norm, especially in the study of medicine.

\section{Declarations}

\section{Acknowledgements}

We would like to thank the faculty members and students who volunteered to participate in the study. We are grateful to the administration of the university that facilitated our work and to the assistant staff who helped in transcribing the recordings of the focus group discussions.

\section{Authors' contributions}


Conceptualization: HA, MHS, AK, AA, and AD; Data curation: HA, MHS, AK, and JA; Data analysis, HA, AJ, and JA; Methods: HA, MHS, AA, AK, JA, and AD; Writing - original draft: HA, MHS, AK, AJ, JA, AA, and AD; Writing - review and editing: $\mathrm{HA}, \mathrm{MHS}, \mathrm{AK}, \mathrm{AA}$, and $\mathrm{AD}$. All authors have reviewed and approved the manuscript.

\section{Funding}

The authors received no funding for this work.

\section{Availability of data and materials}

The data of the current study are available from the corresponding author upon reasonable request.

\section{Declarations}

\section{Ethics approval and consent to participate}

The study was approved by the Research and Ethics Committee of the College of Medicine and Medical Sciences, Arabian Gulf University (Ref. No.: E029-PI-12/20). Filling the survey questionnaire implied the participants' consent to be included in the study. The confidentiality of all the participants was maintained throughout the study.

\section{Consent for publication}

Not applicable.

\section{Competing interests}

The authors declare that they have no competing interests.

\section{References}

1. Mustafa N. Impact of the 2019-20 coronavirus pandemic on education. Int J Health Preferences Res. 2020:1-2. https://doi.org/10.1016/S14733099(09)70176-8

2. Goh PS, Sandars J. A vision of the use of technology in medical education after the COVID-19 pandemic. MedEdPublish. 2020;9. https://doi.org/10.15694/mep.2020.000049.1

3. Liang ZC, Ooi SB, Wang W. Pandemics and their impact on medical training: Lessons from Singapore. Acad Med. 2020;95:135961. https://doi.org/10.1097/ACM.0000000000003441

4. Ahmed SA, Hegazy NN, Malak HW, Kayser WC, Elrafie NM, Hassanien M, et al. Model for utilizing distance learning post COVID-19 using (PACT) ${ }^{\mathrm{TM}}$ a cross sectional qualitative study. BMC Med Educ. 2020;20(1):1-3. https://doi.org/10.1186/s12909-020-02311-1

5. Amin HA, Shehata MH, Ahmed SA. Step-by-step guide to create competency-based assignments as an alternative for traditional summative assessment. MedEdPublish. 
2020;9. https://doi.org/10.15694/mep.2020.000120.1

6. Shehata MH, Abouzeid E, Wasfy NF, Abdelaziz A, Wells RL, Ahmed SA. Medical education adaptations post COVID-19: an Egyptian reflection. J Med Educ Curricular Devel. 2020; 7:2382120520951819. https://doi.org/10.1177\%2F2382120520951819

7. Hall AK, Nousiainen MT, Campisi P, Dagnone JD, Frank JR, Kroeker KI, et al. Training disrupted: practical tips for supporting competency-based medical education during the COVID-19 pandemic. Med Teach. 2020;42(7):756-61. https://doi.org/10.1080/0142159X.2020.1766669

8. Rose S. Medical student education in the time of COVID-19. JAMA. 2020 Jun 2;323(21):21312. https://doi.org/10.1001/jama.2020.5227

9. Taylor D, Grant J, Hamdy H, Grant L. Transformation to learning from a distance. MedEdPublish. 2020;9(1):76. https://doi.org/10.15694/mep.2020.000076.1

10. Vlachopoulos D. COVID-19: threat or opportunity for online education? Higher Learn Res Communications. 2020;10(1):2. https://doi.org/10.18870/hlrc.v10i1.1179

11. Bezerra IM. State of the art of nursing education and the challenges to use remote technologies in the time of corona virus pandemic. J Human Growth Devel. 2020;30(1):141-

7. http://dx.doi.org/10.7322/jhgd.v30.10087

12. Dewart G, Corcoran L, Thirsk L, Petrovic K. Nursing education in a pandemic: Academic challenges in response to COVID-19. Nurse Educ Today. 2020. https://doi.org/10.1016/j.nedt.2020.104471

13. Ting AS, Ho CL. Outbreak Measures Taken by Medical Schools During the Coronavirus Pandemic in London, United Kingdom: A Qualitative Study. 2020 (preprint). https://doi.org/10.21203/rs.3.rs20544/v1

14. Alexander L, Ashcroft J, Byrne MH, Wan J. All hands on deck: early graduation of senior medical students in the COVID-19 pandemic. MedEdPublish. 2020;9. https://doi.org/10.15694/mep.2020.000096.1

15. Sharif SP. UK medical students graduating early to work in the COVID-19 pandemic. Psychol Med. 2020:1-4. https://doi.org/10.1017/S0033291720001488

16. Kumar AP, Al Ansari AM, Shehata MH, Tayem YI, Arekat MR, Kamal AA, et al. Evaluation of curricular adaptations using digital transformation in a medical school in Arabian Gulf during the COVID-19 pandemic. J Microscopy Ultrastructure. 2020;8(4):186. https://doi.org/10.4103/jmau.jmau_87_20

17. Paechter M, Maier B. Online or face-to-face? Students' experiences and preferences in e-learning. Internet Higher Educ. 2010;13(4):292-7. http://dx.doi.org/10.1016/j.iheduc.2010.09.004

18. Paechter M, Maier B, Macher D. Students' expectations of, and experiences in e-learning: Their relation to learning achievements and course satisfaction. Compu Educ. 2010;54(1):222-

9. https://doi.org/10.1016/j.compedu.2009.08.005

19. Muthuprasad T, Aiswarya S, Aditya KS, Jha GK. Students' perception and preference for online education in India during COVID-19 pandemic. Soc Sci Humanities Open.

2021;3(1):100101. https://doi.org/10.1016/j.ssaho.2020.100101

Page 17/19 
20. Al-Azzam N, Elsalem L, Gombedza F. A cross-sectional study to determine factors affecting dental and medical students' preference for virtual learning during the COVID-19 outbreak. Heliyon. 2020;6(12):e05704. https://doi.org/10.1016/j.heliyon.2020.e05704

21. Ehrlich $\mathrm{H}$, McKenney M, Elkbuli A. Strategic planning and recommendations for healthcare workers during the COVID-19 pandemic. American J Emergency Med. 2020;38(7):1446-

7. https://doi.org/10.1016/j.ajem.2020.03.057

22. MacDougall C, Dangerfield P, Katz D, Strain WD. The impact of COVID-19 on Medical education and Medical Students. How and when can they return to placements? MedEdPublish. 2020;9. https://doi.org/10.15694/mep.2020.000159.1

23. Spears LR. Social Presence, Social Interaction, Collaborative Learning, and Satisfaction in Online and Face-to-Face Courses. 2012. Graduate Theses and Dissertations.

12976. https://lib.dr.iastate.edu/etd/12976 (last accessed: August 20, 2021).

24. Akcaoglu M, Lee E. Increasing social presence in online learning through small group discussions. Int Rev Res Open Distributed Learn. 2016;17(3). http://dx.doi.org/10.19173/irrodl.v17i3.2293

25. Lowenthal PR, Dennen VP. Social presence, identity, and online learning: research development and needs. Distance Educ. 2017;38(2):137-140. https://doi.org/10.1080/01587919.2017.1335172

26. Aragon SR. Creating social presence in online environments. New directions for adult and continuing education. 2003(100);57-68.

27. Frazer C, Sullivan DH, Weatherspoon D, Hussey L. Faculty perceptions of online teaching effectiveness and indicators of quality. Nursing Res Practice. 2017;9374189. https://doi.org/10.1155/2017/9374189

28. Walters S, Grover KS, Turner RC, Alexander JC. Faculty perceptions related to teaching online: A starting point for designing faculty development initiatives. Turkish Online J Distance Educ. 2017;18(4):4-19. https://doi.org/10.17718/TOJDE.340365

29. Braun V, Clarke V. Thematic analysis. In: Cooper H, Camic PM, Long DL, Panter AT, Rindskopf D, Sher KJ (Eds.), APA handbooks in psychology ${ }^{\circledR}$. APA handbook of research methods in psychology, Vol. 2. Research designs: Quantitative, qualitative, neuropsychological, and biological (p. 57-71). American Psychological Association, 2012.

30. Keis O, Grab C, Schneider A, Öchsner W. Online or face-to-face instruction? A qualitative study on the electrocardiogram course at the University of Ulm to examine why students choose a particular format. BMC Med Educ. 2017;17(1):1-8. https://doi.org/10.1186/s12909-017-1053-6

31. Butnaru GI, Niță V, Anichiti A, Brînză G. The Effectiveness of Online Education during Covid 19 Pandemic-A Comparative Analysis between the Perceptions of Academic Students and High School Students from Romania. Sustainability. 2021;13(9):5311. https://doi.org/10.3390/su13095311

32. Lapitan Jr LD, Tiangco CE, Sumalinog DA, Sabarillo NS, Diaz JM. An effective blended online teaching and learning strategy during the COVID-19 pandemic. Educ Chemical Engineers. 2021;35:116-31. https://doi.org/10.1016/j.ece.2021.01.012 
33. Prober CG, Khan S. Medical education reimagined: a call to action. Acad Med 2013; 88:140710. https://doi.org/10.1097/acm.0b013e3182a368bd

34. Chowdhury TA, Khan H, Druce MR, Drake WM, Rajakariar R, Thuraisingham R, et al. Flipped learning: Turning medical education upside down. Future Healthcare J. 2019;6(3):192. https://doi.org/10.7861/fhj.2018-0017

\section{Figures}

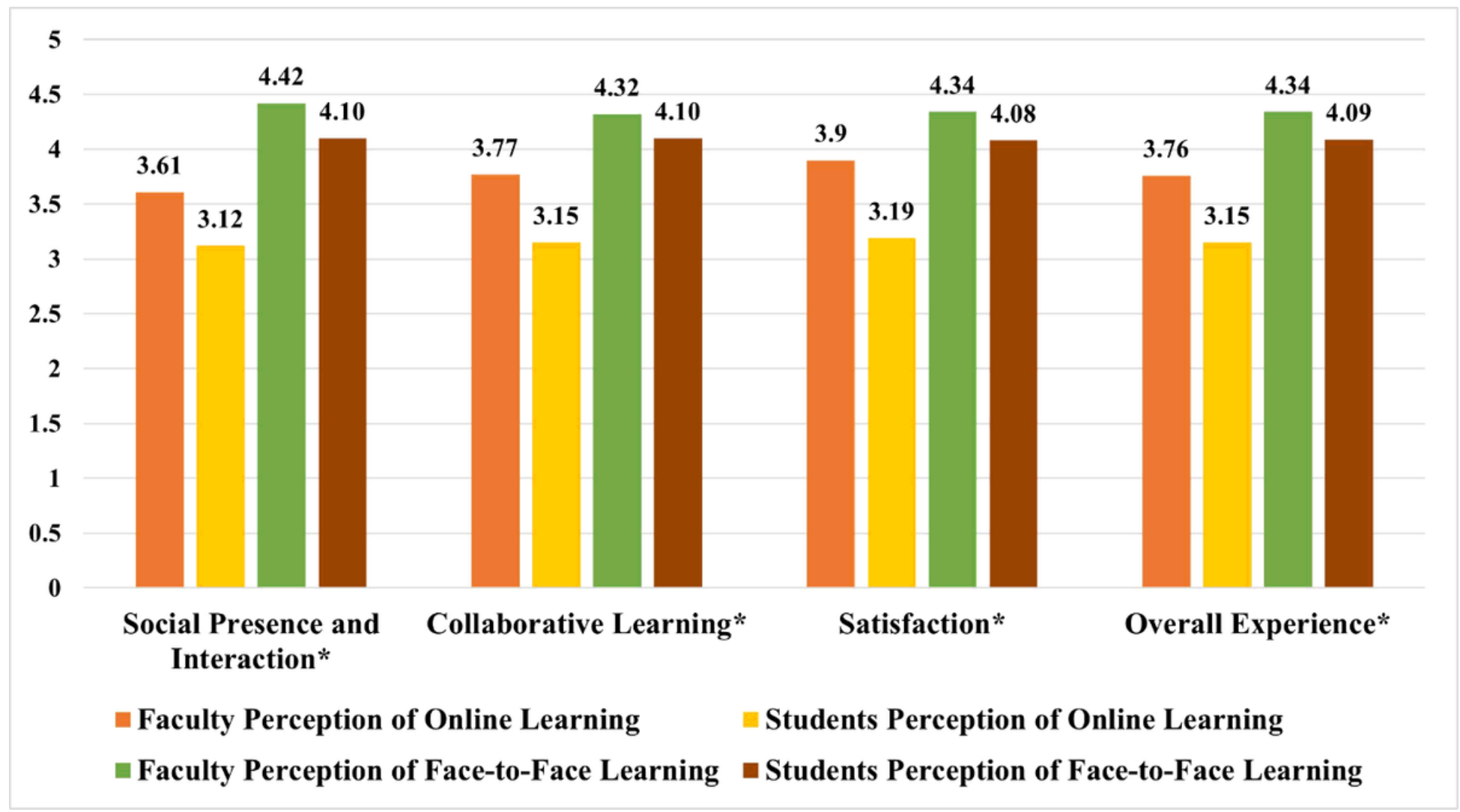

Figure 1

Comparison between the Responses of Faculty Members and Students on Online and Face-to-Face Learning regarding Social Presence and Interaction, Collaborative Learning, Satisfaction, and the Overall Experience 